\title{
A Efetividade de Feedbacks I nformatizados Sobre a Autoregulação da Aprendizagem em Cursos a Distância: um estudo de caso na área da computação
}

Luis Fernando Máximo

Orientador: Dante Augusto Couto Barone

Coorientadora: Marie Jane Soares Carvalho

Um dos maiores problemas para a consolidação de uma educação a distância que tenha boa qualidade do ensino e da aprendizagem é a questão da avaliação e do acompanhamento dos alunos. Na educação a distância o acesso direto aos professores é menos freqüente e existe uma quantidade de alunos normalmente maior do que na educação presencial. Portanto, boa parte do tempo o aluno depende de si e dos recursos que tem à sua disposição para trilhar seu caminho de aprendizagem. A literatura sobre avaliação na educação a distância, em geral, tem apontado a necessidade da adoção de uma concepção de avaliação que seja formativa por parte dos tutores e professores e que permita aos estudantes a auto-regulação do seu próprio processo de aprendizagem. Mas, se já é difícil aplicar tais ideais avaliativos na educação presencial, na educação a distância a tarefa é das mais complicadas. Essa discussão tem seu reflexo na área de Informática na Educação em forma de pesquisas sobre como produzir e interpretar registros que possam subsidiar a regulação da aprendizagem por parte dos professores. Da mesma forma existe um esforço em especializar e aperfeiçoar formas de comunicar aos alunos seus avanços e dificuldades. Ambientes adaptativos, objetos de aprendizagem, ferramentas para exercícios e testes informatizados têm surgido como uma alternativa para minimizar as lacunas abertas pelo desequilíbrio quantitativo da relação professor-aluno na educação a distância. Entretanto, não temos garantias de que os feedbacks providos pelos recursos informatizados estejam possibilitando efetivamente a auto-regulação da aprendizagem de alunos em cursos a distância. Considerando que este assunto não pode ser tratado de forma única e generalizada para todas as disciplinas e áreas do conhecimento optamos em realizar nossa pesquisa a partir de uma situação de ensino e aprendizagem a distância na área da Computação. Estabelecemos como objetivo geral do trabalho analisar a efetividade de feedbacks informatizados sobre a auto-regulação da aprendizagem em um de curso superior a distância na área de Computação. A análise se deu a partir do desenvolvimento de um estudo de caso. $\mathrm{O}$ caso estudado constituiu-se da observação de registros provenientes da interação de alunos com uma ferramenta para a exercitação da construção de algoritmos em um curso superior de Tecnologia em Análise e Desenvolvimento de Sistemas a distância. Comparamos os registros de feedbacks fornecidos pela ferramenta com o alcance do objetivo do aluno construir um algoritmo sem erros em tempo de execução. Conjuntamente analisamos o projeto pedagógico do curso que, à época deste estudo, atendia aproximadamente cinco mil alunos dispersos no território nacional. Para a análise e a discussão dos dados coletados foi construída uma fundamentação teórica tratando sobre educação a distância, avaliação e mediação da aprendizagem. A partir dos resultados de testes estatísticos de significância e correlação analisamos, dentro das condições de comunicação, estrutura e autonomia do curso, a efetividade dos feedbacks informatizados sobre a auto-regulação da aprendizagem dos alunos. Esperamos que esta tese possa contribuir para a criação de recursos e sistemas informatizados capazes de ajudar estudantes a assumirem papéis mais ativos e determinantes nos seus próprios processos de aprendizagem, sobretudo, em cursos a distância.

Palavras-chave: Avaliação da aprendizagem. Ensino à distância. Informática na educação.

Referência: MÁXIMO, Luis Fernando. A Efetividade de Feedbacks Informatizados Sobre a Autoregulação da Aprendizagem em Cursos a Distância: um estudo de caso na área da computação. Orientador: Dante Augusto Couto Barone. Coorientadora: Marie J ane Soares Carvalho. 2009. Tese (doutorado) - Programa de Pós-Graduação em Informática na Educação, Centro de Estudos Interdisciplinares em Novas Tecnologias da Educação, Universidade Federal do Rio Grande do Sul, 2009, Porto Alegre. 